\title{
Research on Insulator selection and comparison
}

\author{
Xianri Wang ${ }^{1}$, Xinmin $\mathrm{Yu}^{2}$ \\ ${ }^{1}$ Power System and Automation, Fujian electric power economic research institute, FuZhou, FuJian, 350000, China \\ ${ }^{2}$ Structural engineering, Fujian electric power economic research institute, FuZhou, FuJian, 350000, China
}

\begin{abstract}
The selection of insulator is analyzed and studied in detail in combination with climate and pollution. In this paper, several comparison and selection schemes are studied in detail from the aspects of electrical performance, mechanical performance, economic performance and so on. Through the analysis of the whole life cycle and the combination of the actual situation of the project, the reasonable selection of insulators is carried out to make use of insulators to reach the optimal.
\end{abstract}

\section{Introduction}

At present, insulators for overhead power lines can be divided into glass insulators, porcelain insulators and composite insulators according to their materials. Glass insulator and porcelain insulator are inorganic insulators. Their internal atoms are composed of ionic bonds, which have strong chemical stability and good resistance to arc burning and corrosion. But its surface hydrophobicity is not good easy to be contaminated after being affected with damp. The inside of composite insulator is composed of covalent bonds and the force is weak.
However, it has the advantages of light weight, high mechanical strength and good pollution resistance.

\section{Insulator selection}

Usually adopt domestic overhead transmission lines insulator porcelain plate, plate toughened glass insulator, rod type composite insulator, three types of insulator abroad (Germany, Japan and the United States) not long rod breakdown structure is used in great quantities in the porcelain insulator, the domestic has started production, in east China $500 \mathrm{kV}$ lines for use in our country.

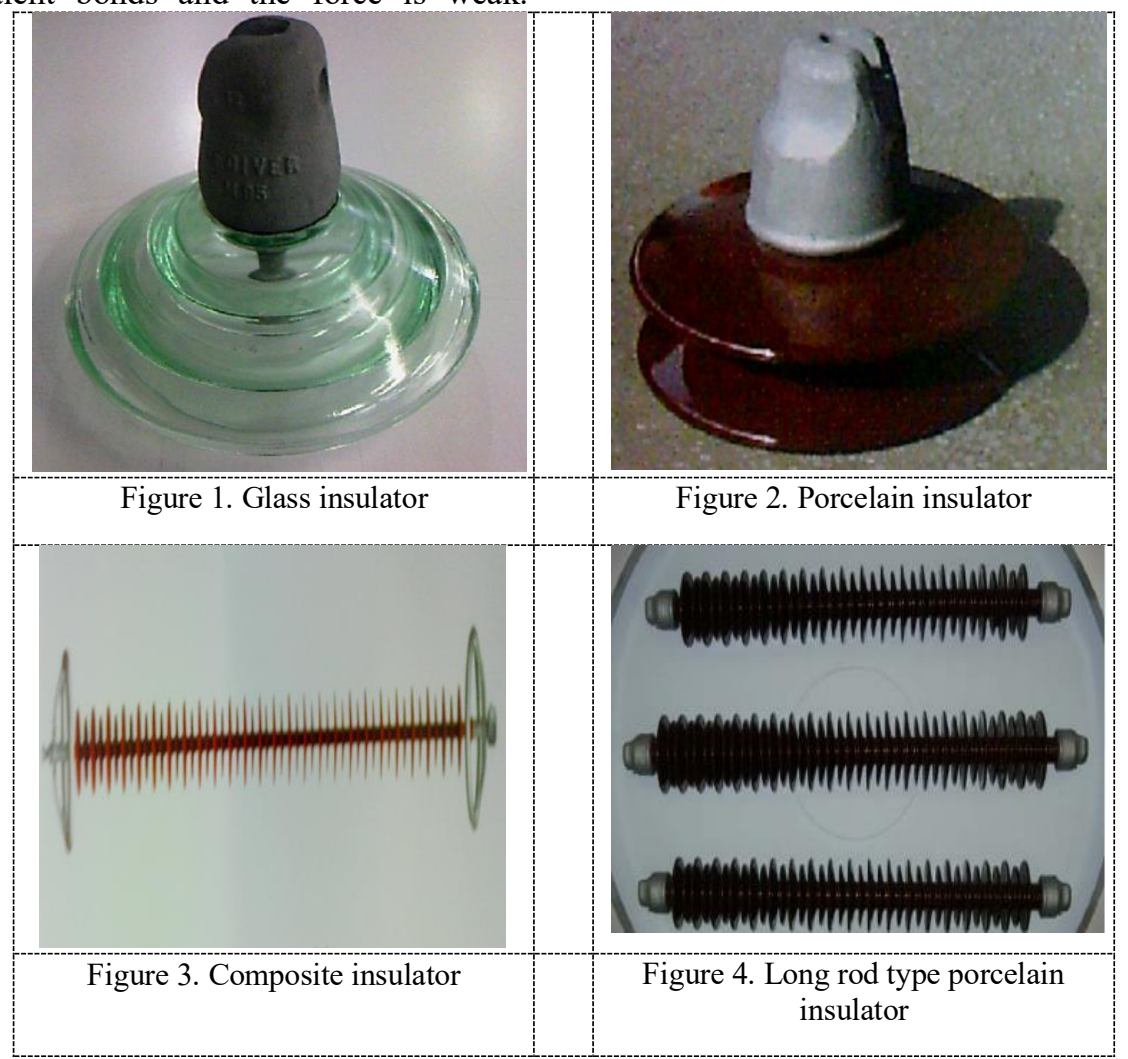

*E-mail: 33067934@qq.com 
Insulator coating (RTV) processing can be used to prevent heavy polluted insulator pollution flashover, the insulator with room temperature curable silicone rubber antifouling flashover dope industry standards (DL/T627-2004), the provisions of the insulator with room temperature curing (RTV) silicone rubber antifouling flash coating of the basic rules of technical requirements, test, test method, packing and storage, selection principles, acceptance, construction, operation maintenance, etc., it is valid for 5 years or so, can be coated again and again.

After adding hydrophobic coating on the outer surface of the insulator, the relationship between the conductivity of the fouling layer and the relative flashover voltage is shown in the figure below.

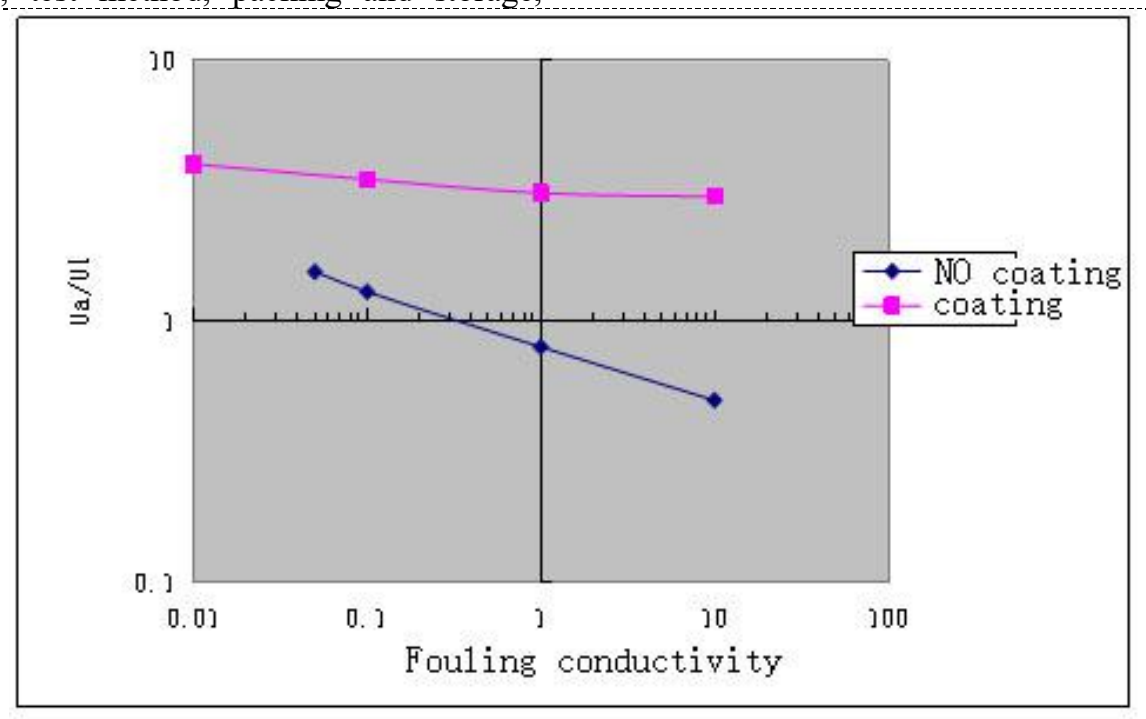

Figure 5. The relationship between the conductivity of fouling layer and flashover voltage

The above figure shows the comparison of pollution resistance of coated insulators and uncoated insulators after 5 years of use when the pollutants are highly conductive, which clearly shows that coated insulators are superior to uncoated insulators in terms of pollution resistance. At present, PRTV coating technology is generally adopted as one of the anti-pollution flashover measures for the operation of established lines, and it is not used as the basis for selecting insulator type for the newly designed lines.

\section{Comparison of insulators}

For the study of different disk insulator pollution flashover performance of China's electricity institute for porcelain, glass, bell, outside the umbrella insulator pollution lightning pressure test and research, according to China's electricity institute of disc insulator pollution lightning pressure test, get different insulator in filthy conditions, different artificial contamination flashover characteristic curve as shown in the figure below.

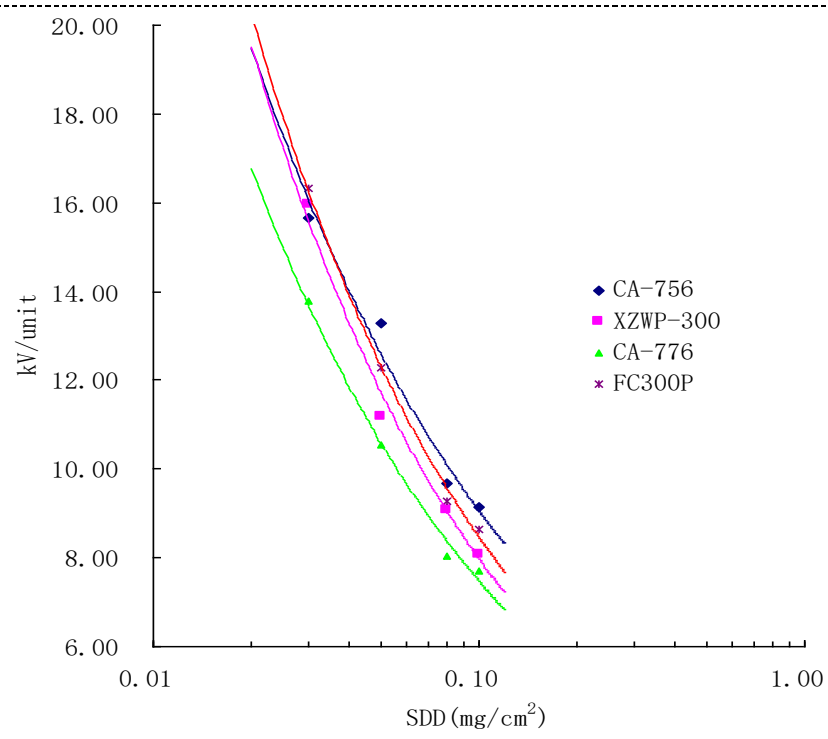

Figure 6. artificial pollution characteristic curve of insulator 
According to the test analysis, the pollution lightning pressure of bell jar porcelain insulator and glass insulator is obviously higher than that of double and triple umbrella insulator. Though the glass bell jar type insulator creepage distance is the largest, but compared with the porcelain insulator as bell jar type, the part between the underside edges is generally low, vulnerable to sub arc, causing the glass insulator creepage distance of effective utilization rate is low, the single insulator flashover voltage is slightly lower than the bell jar type porcelain insulator, about $6.7 \% \sim 7.2 \%$ lower.

The flashover voltage of the outside umbrella insulator is similar to that of the double umbrella insulator. For double umbrella insulators, although the climbing distance is small, it is not easy to be connected by arc because of the large spacing between the two umbrellas, so the climbing distance has a high effective utilization rate. In contrast, the space between the two umbrellas on the top of the three-umbrella porcelain insulator is very small, which is easy to be short connected. Moreover, the middle part of the two umbrellas is very deep, which leads to the loss of a large part of the climbing distance. Therefore, although the climbing distance is very large, the effective climbing distance is very small, and the flashover voltage is not high.

With porcelain porcelain composite insulator core plate and steel cap, steel foot in insulation parts, with a forming, completely sealed for external insulation of high temperature vulcanization silicone rubber umbrella skirt, is retained on the mechanical properties of the porcelain insulator is stable and reliable, and has excellent electrical performance of composite insulator, stable and reliable mechanical connection, excellent resistance to fouling on electrical insulation; And explosive is easy to identify, do not drop, prevent injury accident, the service life of up to 20 years, so only need to replace one according to the characteristics of the above all kinds of insulator and conductor selection of insulator strength requirements, filth along specific features and pollution area, porcelain insulator (standard, umbrella, bell jar type, long bar), glass insulator (standard, bell jar type), composite insulator and porcelain composite insulator dirt deposition characteristics respectively and self-cleaning performance, considering the atmospheric pollution in our country along with the increasing industrial development, lines flashing will be to cause significant damage to the system, Therefore, it is necessary to adopt the rod composite insulator or porcelain composite insulator to improve the pollution flashover resistance of the insulator string, so as to ensure the reliable and safe operation of the transmission line. Secondly, due to the excellent hydrophobicity, the climbing distance of the rod composite insulator or porcelain composite insulator can be shortened in application (the climbing distance of porcelain insulator can be $75 \%$ in heavy pollution areas), the length of the insulator can be shortened, the size of the tower head can be effectively reduced, and the project cost can be reduced. In addition, the price of wand-shaped composite insulators is also cheaper than that of porcelain and glass insulators. The investment in the whole life cycle of porcelain composite insulators in heavy pollution areas is better than that of ordinary porcelain insulators. The use of wand-shaped composite insulators or porcelain composite insulators themselves can save costs. Third, the maintenance and operation of the application of the rod composite insulator or porcelain composite insulator in the later period is relatively simple, which can effectively eliminate the cleaning and zero-value detection of the porcelain insulator used in the line, and greatly reduce the workload and cost of operation and maintenance. It has obvious economic and technical advantages to use the rod composite insulator or porcelain composite insulator on the high voltage line.

In conclusion, after comprehensive comparison of mechanical and electrical properties and economic indicators of various types of insulators, in order to facilitate maintenance and overhaul of operating units, and in combination with comprehensive comparison and selection results of whole-life cycle insulators in similar projects, the design recommends the use of rod suspended composite insulators in suspension strings and jumper strings of this project. Considering that there is a risk of string dropping due to the brittle breaking of the mandle-shaped composite insulator, it is not recommended to choose the composite rod insulator for tension-proof string, instead, it is recommended to adopt the dish suspended porcelain insulator or the dish suspended porcelain composite insulator for tension-proof string.

\section{The conclusion}

Combined with the climate and pollution of the route, the selection of insulator in this project is analyzed and studied in detail. From the electrical performance, mechanical performance, economic performance and other aspects of a number of comparison and selection programs were studied in detail, we can through the whole life cycle analysis, and combined with the actual situation of the project for the reasonable selection of insulator, so that the project insulator use to reach the optimal.

\section{References}

1. Kawamura T, Ishii $M$, Akbar $M$ and Nagai $K$. Pressure Dependence of DC Breakdown of Contaminated Insulators[J]. IEEE Transactions on Electrical Insulation, 1982, 17(1): 39-45.

2. Mizuno Y, Kusada H, and Nagai K. Effect of climatic conditions on contamination flashover voltageof insulators[J]. IEEE Transactions on Electrical Insulation, 1997, 4(3): 286-289

3. K.L. Chrzan, J. Vokalek, V. Sklenicka, et al. Pollution flashover of long rod insulators with differentprofiles[J]. 8th ISH, Netherlands, 2003: 1-4.

4. J. M. Seifert, W. Petrusch and H. Janssen. A Comparison of the Pollution Performance of Long Rodand Disc Type HVDC Insulators[J]. IEEE 
Transactions on Dielectrics and Electrical Insulation, 2007,14(1): 125-129.

5. Sun Zhaoying, Su Zhiying. Pollution flashover and selection of insulators used on transmission lines in China 2001 World Insulator Congress and Exhibition.

Shanghai, China: INMR Journal Press, 2001 